\title{
Seroprevalence of hepatitis A immunity among Brazilian adult patients with liver cirrhosis: is HAV vaccination necessary?
}

\section{Authors}

Luiz Carlos Marques de Oliveira ${ }^{1}$

Samantha Martins Comácio $^{2}$

Júlia de Fátima Gonçalves Santos $^{3}$

${ }^{1} \mathrm{MSc}, \mathrm{PhD}$; Professor, Department of Internal Medicine, Medical School, Universidade Federal de Uberlândia, MG, Brazil ${ }^{2} \mathrm{MD}$; Resident Physician (R2) in Internal Medicine, Medical School, Universidade Federal de Uberlândia, MG, Brasil ${ }^{3} \mathrm{MSc}$ in Health

Sciences; Physician at Gastroenterology Service, Hospital de Clínicas,

Universidade Federal de Uberândia, MG, Brazil
Submitted on: $08 / 26 / 2010$ Approved on: 10/23/2010

\footnotetext{
Correspondence to: Luiz Carlos Marques de Oliveira

Rua Gonçalves Dias, 455 Tabajaras, Uberlândia MG - 38400-288 Fone/fax: (34) 3218.2246 oliveiralcm@ufu.br
}

Financial Support: FAEPU (Fundação de Assistência, Estudo e Pesquisa de Uberlândia)

We declare no conflict of interest.

\begin{abstract}
Background: Patients with chronic liver disease have a higher risk of fulminant hepatitis when infected with hepatitis A virus, and vaccination of these patients against such infection is recommended. In Brazil, mainly in the South and Southeast regions, the epidemiology of hepatitis A (HA) has shifted from high to intermediate endemicity, which would have implication on policy of HA vaccination for these populations. Objective: To verify the prevalence of HA immunity in adult patients with liver cirrhosis (LC), in Uberlândia MG, a city of Southeastern Brazil. Methods: Between December 2005 and December 2006, 106 patients with LC were consecutively evaluated. In addition, 75 individuals without LC or alcoholism were evaluated (control group - CG). Results: Total anti-HAV (ELISA methods) was positive in 104 (98.1\%) patients with LC (82 men, 24 women; mean age, $53.3 \pm 11.9$ years) and in 74 (98.7\%) individuals of the CG (55 men, 20 women; mean age, $47 \pm 11.6$ years), $p>0.05$. Conclusions: For patients with chronic liver disease, in the geographic regions and age groups evaluated, routine vaccination against hepatitis $\mathrm{A}$ is not recommended. Moreover, the serum determination of total anti-HAV, used to assess immunity, is five times cheaper than vaccination against hepatitis $A$ and, for this reason, should precede vaccination.
\end{abstract}

Keywords: hepatitis A vaccines; hepatitis A virus; liver cirrhosis; prevalence.

[Braz J Infect Dis 2011;15(3):268-271] CElsevier Editora Ltda.

\section{INTRODUCTION}

Hepatitis A virus (HAV) infection is a global disease caused by a picornavirus transmitted via the fecal-oral route, by person-to-person contact, or ingestion of contaminated food or water. Most infections are asymptomatic in children under 6 years of age, whereas this infection is usually symptomatic among older children and adults, with signs and symptoms that usually last less than 2 months. The casefatality rate for fulminant hepatitis A among persons of all ages is approximately $0.3 \%{ }^{1}$

Hepatitis A (HA) is a very common infection of the early years of life in developing countries of Asia, Africa, and Latin America, where seroprevalence rates approach 100\% and most infections occur by 5 years of age. ${ }^{2}$ However, in several geographic areas, there have been changes in the epidemiology of HA, such as Southeast Asia and China. A number of countries have shifted from high to intermediate and from intermediate to low endemicity, as a result of advances in hygiene, sanitation and the quality of drinking water, reflecting improvements in living standards and socioeconomic progress. ${ }^{3}$

In Brazil, a multicenter study found intermediate endemicities in the Southern and Southeastern regions (anti-HAV prevalence rates of 55.7\%) and in the Northeastern region $(76.5 \%)$ and high endemicity in the Northern region $(92.8 \%) .{ }^{4}$ In other studies performed in cities of Southeastern Brazil, the following seroprevalences of anti-HAV were observed: $32.1 \%$ in individuals aged between 1 and 23 years, in Rio de Janeiro, RJ; ${ }^{5} 38.6 \%$ in children aged between 4 and 14 years, in Vila Velha, $\mathrm{ES} ;{ }^{6}$ and $54.2 \%$ in adolescents aged between 10.4 and 19.9 years, in São Paulo, SP. ${ }^{7}$ Lower exposure to HAV in childhood causes adults to be vulnerable to such infection, when the disease has a higher morbidity. The case-fatality rate for fulminant $\mathrm{HA}$ is $1.8 \%$ among adults older than 50 years. 
Although not at increased risk for HAV infection, persons who have chronic liver disease are at increased risk for fulminant HA, with a higher fatality rate. ${ }^{1}$ During a large outbreak of HA that took place in Shanghai, China, in the late 1980s, a 5.6-fold higher fatality rate was reported among chronic HBsAg carriers than among patients without HBV infection. In addition, in the United States, between 1983 and 1988, a total of 115,551 cases of acute HA were reported to the Centers for Disease Control and Prevention (CDC) and a 58.5-fold higher fatality rate was found among chronic HBsAg carriers than among patients without HBV infection. ${ }^{8}$ Furthermore, patients with chronic active hepatitis B or cirrhosis more likely have a worse outcome from HA than healthy HBsAg carriers. ${ }^{8}$ Acute HA, when occurring in patients with underlying chronic hepatitis $\mathrm{C}$, may also cause significantly increased morbidity and mortality. ${ }^{9}$ In one study, fulminant HA was described in $41.2 \%$ of the 17 HCV-infected patients, with a mortality rate of $35.3 \%{ }^{10}$ Patients with other chronic liver diseases also appear to be at increased risk for more severe disease with superimposed HA. ${ }^{9}$ Fulminant hepatic failure during acute HA was described in patients who were injecting drug users and had alcoholic liver cirrhosis. ${ }^{11}$

To minimize the occurrence of acute $\mathrm{HA}$ in patients with chronic liver disease, a variety of organizations have recommended HA vaccination for these patients. ${ }^{9}$ The present study aimed to verify the prevalence of HA immunity in patients with liver cirrhosis (LC), in a city of Southeastern Brazil, with the purpose of verifying a vaccination strategy against hepatitis A for these patients.

\section{METHODS}

Between December 2005 and December 2006, 106 patients with LC were prospectively and consecutively evaluated at the Hospital de Clínicas da Universidade Federal de Uberlândia (HC-UFU), in the city of Uberlândia, state of Minas Gerais, Southeastern Brazil.

A total of 82 (77.4\%) of the evaluated patients were male and $24(22.6 \%)$ were female; the mean age was $53.3 \pm 11.9$ years (age range from 22 to 87 years). Diagnosis of LC was based on liver biopsy, except in those patients whose coagulation disorders did not permit this type of test. In these cases, the diagnosis was based on clinical and laboratory criteria and on imaging tests (ultrasound and/or computed tomography). LC etiology was based on clinical history and specific laboratory tests. The diagnosis of cryptogenic LC was made when no etiology could be identified.

Most patients with LC evaluated had an alcoholic etiology. In a previous work, ${ }^{12}$ alcoholics who sought treatment at the Alcohol Outpatient Clinic of the HC-UFU were found to have a high prevalence of serological markers of hepatitis $\mathrm{B}$ virus (HBV) and hepatitis $\mathrm{C}$ virus (HCV), and, as a result, they could also show higher seroprevalence of HAV infection. For this reason, although this study was not designed to be a case-control study, another group was also evaluated, with 75 non-alcoholic individuals without evident chronic liver disease, who were cared for at the HC-UFU's Department of Traumatology Outpatient Clinic. Of these, 55 (73.3\%) were male and 20 (26.7\%) were female; the mean age was $47.0 \pm$ 11.6 years (age range from 23 to 79 years). The positive or negative diagnosis of alcoholism was confirmed by clinical history and by the CAGE (Cutdown, Annoyed by criticism, Guilty and Eye-opener) questionnaire, which was applied to each patient to diagnose chronic abuse of or dependence on alcohol. CAGE was positive when two or more affirmative responses were given to its four questions. ${ }^{13}$

The minimum calculated sample size was 74 individuals, assuming a anti-HAV seroprevalence for the adult population in this region of $95 \%$, error of $5 \%$ and $95 \%$ confidence.

Blood samples were subsequently collected from each patient who agreed to participate in the study and, after centrifugation, serum was stored at $-20^{\circ} \mathrm{C}$. The technique used to detect hepatitis A serological markers were the use of microparticle enzyme immunoassay (Abbott, AxSYM system, Wiesbaden, Germany) for qualitative detection of total antiHAV (HAVAB 2.0) and IgM anti-HAV (HAVAB - M 2.0).

One patient, who claimed to have been vaccinated against HA, was not included in the present study. This project was approved by the institutional research ethics committee and an informed consent form was signed by each patient for their participation. Student's $t$ test was used to compare means of ages and Fisher's exact test, to compare frequencies of immunity between both groups evaluated. A p $<0.05$ was considered significant.

\section{RESULTS}

The frequency of LC etiologies in males, females and global were, respectively: alcohol (64.6\%, 37.5\% and 58.5\%); alcohol and HCV (14.6\%, 0 and 11.3\%); HBV (8.5\%; 8.3\% and $8.5 \%)$; HCV (3.7\%, $12.5 \%$ and 5.7\%); alcohol and HBV (2.4\%; $4.2 \%$ and $2.8 \%)$, autoimmune hepatitis $(0,4.2 \%$ and $0.9 \%)$; nonalcoholic steatohepatitis $(0,4.2 \%$ and $0.9 \%)$ and cryptogenic (6.1\%, 29.2\% and $11.3 \%)$.

Patients with alcoholic LC, separately or associated with $\mathrm{HBV}$ or HCV, consumed $325 \pm 214 \mathrm{~g}$ of ethanol per day and a minimum of $100 \mathrm{~g} /$ day, during a mean time of $28 \pm 11$ years and a minimum of 10 years, and their CAGE questionnaire was positive. In the control group, the history of alcohol abuse and the results of the CAGE questionnaire were negative for all patients.

Total anti-HAV was positive in 104/106 (98.1\%) patients with LC and IgM anti-HAV was negative in all of them; in the control group, total anti-HAV was positive in 74/75 (98.7\%) individuals and IgM anti-HAV was positive in 1 $(\mathrm{p}>0.05)$ as shown in Table 1 . 
Table 1. Frequency of antibodies against HAV in patients with liver cirrhosis and in the control group

\begin{tabular}{|c|c|c|c|c|c|c|c|}
\hline \multirow[t]{2}{*}{ Anti-HAV } & \multicolumn{3}{|c|}{ Liver cirrhosis } & \multicolumn{3}{|c|}{ Control group } & \multirow[t]{2}{*}{ p value* } \\
\hline & $\begin{array}{l}\text { Male } \\
\text { n (\%) }\end{array}$ & $\begin{array}{c}\text { Female } \\
\text { n (\%) }\end{array}$ & $\begin{array}{l}\text { Total } \\
\text { n (\%) }\end{array}$ & $\begin{array}{l}\text { Male } \\
\text { n (\%) }\end{array}$ & $\begin{array}{c}\text { Female } \\
\text { n (\%) }\end{array}$ & $\begin{array}{l}\text { Total } \\
\text { n (\%) }\end{array}$ & \\
\hline \multicolumn{8}{|l|}{ IgM } \\
\hline Positive & 0 & 0 & 0 & 0 & $1(5)$ & $1(1.3)$ & 0.41 \\
\hline Negative & $82(100)$ & $24(100)$ & $106(100)$ & $55(100)$ & $19(95)$ & $74(98.7)$ & \\
\hline \multicolumn{8}{|l|}{ Total } \\
\hline Positive & $80(97.6)$ & $24(100)$ & $104(98.1)$ & $54(98.2)$ & $20(100)$ & $74(98.7)$ & 1.00 \\
\hline Negative & $2(2.4)$ & 0 & $2(1.9)$ & $1(1.8)$ & 0 & $1(1.3)$ & \\
\hline
\end{tabular}

* Fisher's exact test: liver cirrhosis group = control group

Among patients with LC, 9 (8.5\%) reported they had already had hepatitis and the LC etiologies in those patients were as follows: $\mathrm{HBV}$ in 4, HBV and alcohol in 2, HCV in 2 and $\mathrm{HCV}$ and alcohol in 1; etiology (HBV) was confirmed by serological tests during acute illness in only one of them. In the control group, no patients remembered having had hepatitis.

There was no significant difference in mean age between both groups evaluated. All individuals had a similar background. However, the frequency of monthly family income of up to three minimum wages was higher $(\mathrm{p}<0.05)$ among patients with LC (80.4\%) than among those of the control group (60.3\%).

The ages of patients with $\mathrm{LC}$ and negative total anti-HAV were 50 years and 73 years, and the LC etiologies were alcohol and alcohol and HBV, respectively. The only individual in the control group with this negative test was 34 years old.

\section{DISCUSSION}

No differences in frequencies of HA immunity were found between patients with LC and the control group. This is in agreement with reports stating that patients with chronic liver disease do not have higher risk of being infected with HAV than the general population. ${ }^{1}$ In addition, the control group was initially proposed to verify whether patients with LC of an alcoholic etiology had higher seroprevalence of HAV infection, as has been observed with regard to the virus of hepatitis B or C. ${ }^{12}$ Curiously, the only two patients with LC and negative anti-HAV had an alcoholic etiology.

When patients with chronic liver disease acquire HAV infection, they have higher risk of fulminant hepatitis and death. The reason why patients with chronic liver disease have more frequent fulminant hepatitis during acute illness by HAV is not clear. It was speculated that acute HAV in- fection may trigger autoimmune mechanisms in susceptible patients, which may increase liver damage due to hepatitis A and lead to massive necrosis of hepatocytes. ${ }^{10}$ During fulminant HA, people with chronic HBV infection were found to show transient appearance of anti-HBs and disappearance of $\mathrm{HBsAg}^{14}$ and, moreover, HBV DNA may become undetectable during the infection and again be detected after recovery from acute hepatitis A. ${ }^{10}$ In patients with chronic hepatitis C and fulminant hepatitis after HAV superinfection, serum HCV RNA can be undetectable during acute illness and become detectable again after these patients are cured of HA. ${ }^{10}$ The mechanism by which circulating viral markers are decreased is unknown; it is speculated that this may occur as a result of necrosis of hepatocytes harboring replicating hepatitis virus. ${ }^{14}$

Thus, people who have chronic liver disease should be vaccinated against HAV. The response to HAV vaccination in chronic liver disease is optimal when aimed at patients before hepatic decompensation develops, i.e. in patients with chronic hepatitis or patients with liver cirrhosis ChildPugh class A, a $98 \%$ response rate was observed after full course of vaccination, compared with a rate of $65.7 \%$ in patients with decompensated liver disease. ${ }^{15}$

In the present study, the seroprevalence of HAV infection in patients with LC was as high as that observed in other developing countries, such as India, where, due to the high frequency of HA immunity among patients with LC, authors do not recommend routine vaccination. ${ }^{16,17}$ These results are also similar to those of another study, performed in patients with chronic HCV infection (median age of 50 years, age range from 4 to 81 years), in the state of Pernambuco, Northeastern Brazil, where HA immunity was observed in $96 \%$ of patients. For this reason, authors of this study recommend anti-HAV testing before vaccination against HAV as a cost-effective strategy. ${ }^{18}$ However, these results are higher 
than those observed in patients with HCV infection (mean age of 44.8 years), in the city of Rio de Janeiro (86\%), leading authors of this other study to recommend implementation of hepatitis A vaccination for this population. ${ }^{19}$

Thus, despite the observed changes in the HA epidemiology from high to intermediate endemicity in the Southeastern Brazil, the high seroprevalence of anti-HAV antibodies in adult patients with LC observed in the present study shows that routine HA vaccination could not be implemented for this patients. In addition, the serological test for total anti-HAV detection by ELISA method is five times cheaper than complete vaccination against hepatitis A [R $\$ 35.00$ (US\$19.4) versus R\$180.00 (US\$100), respectively], and, for these reasons, the screening for HAV antibody before vaccination could be recommended for adult patients with chronic liver disease due to its higher cost-effectiveness.

\section{ACKNOWLEDGEMENTS}

Authors would like to thank Edil Roberto de Faria and Sinval José Silva, professionals from the clinical analysis laboratory at the HC-UFU, for performing the determinations of serological tests.

\section{REFERENCES}

1. Prevention of hepatitis A through active or passive immunization: Recommendations of the advisory committee on immunization practices (ACIP). MMWR Recomm Rep. 1999; 48(RR-12):1-37.

2. Koff RS. Hepatitis A. Lancet 1998; 351:1643-9.

3. Barzaga NG. Hepatitis A shifting epidemiology in South-East Asia and China. Vaccine 2000; 18:S61-S64.

4. Clemens SAC, Fonseca JC, Azevedo T et al. Soroprevalência para hepatite A e hepatite B em quatro centros no Brasil. Rev Soc Bras Med Trop. 2000; 33:1-10.

5. Vitral CL, Yoshida CFT, Lemos ERS, Teixeira CS, Gaspar AMC. Age-specific prevalence of antibodies to hepatitis A in children and adolescents from Rio de Janeiro, Brazil, 1978 and 1995. Relationship of prevalence to environmental factors. Mem Inst Oswaldo Cruz 1998; 93:1-5.
6. Zago-Gomes MP, Stantolin GC, Perazzio S, Aikawa KH, Gonçalves CS, Pereira FEL. Prevalence of anti-hepatitis A antibodies in children of different socioeconomic conditions in Vila Velha, ES. Rev Soc Bras Med Trop. 2005; 38:285-9.

7. Dinelli MIS, Fisberg M, Moraes-Pinto MI. Anti-hepatitis A virus frequency in adolescents at an outpatient clinic in São Paulo, Brazil. Rev Inst Med Trop S. Paulo 2006; 48:43-4.

8. Keeffe EB. Is hepatitis A more severe in patients with chronic hepatitis B and other chronic liver diseases? Am J Gastroenterol. 1995; 90:201-5.

9. Reiss G, Keeffe EB. Review article: hepatitis vaccination in patients with chronic liver disease. Aliment Pharmacol Ther. 2004; 19:715-27.

10. Vento S, Garofano T, Renzini C et al. Fulminant hepatitis associated with hepatitis $\mathrm{A}$ virus superinfection in patients with chronic hepatitis C. N Engl J Med. 1998; 338:286-90.

11. Akriviadis EA, Redeker AG. Fulminant hepatitis A in intravenous drug users with chronic liver disease. Ann Intern Med. 1989; 110:838-9.

12. Oliveira LCM, Buso AG, Oliveira AT, Arantes CA, Borges LV, Valente, SRG. Prevalence of hepatitis B and hepatitis C markers in alcoholics with and without clinically evident hepatic cirrhosis. Rev Inst Med Trop. São Paulo 1999; 41:69-73.

13. Ewing JA. Detecting alcoholism. The CAGE questionnaire. JAMA 1984; 252:1905-7.

14. Wang JY, Lee SD, Tsai YT, Lo KJ, Chiang BN. Fulminant hepatitis A in chronic HBV carrier (letter). Dig Dis Sci. 1986; 31:109-11.

15. Arguedas MR, Johnson A, Eloubeidi MA, Fallon MB. Immunogenicity of hepatitis A vaccination in decompensated cirrhotic patients. Hepatology 2001; 34:28-31.

16. Acharya SK, Batra Y, Bhatkal B et al. Seroepidemiology of hepatitis A virus infection among school children in Delhi and north Indian patients with chronic liver disease: implications for HAV vaccination. J Gastroenterol Hepatol. 2003; 18:822-7.

17. Duseja A, Sharma S, Das K, Dhiman RK, Chawla YK. Is vaccination against hepatitis $A$ virus required in patients with cirrhosis of the liver? Trop Gastroenterol. 2004; 25:162-3.

18. Villar LM, Melo MMM, Calado IA, Almeida AJ, Lampe E, Gaspar AMC. Should Brazilian patients with chronic hepatitis $\mathrm{C}$ virus infection be vaccinated against hepatitis A virus? J Gastroenterol Hepatol. 2009; 24:238-42.

19. Devalle S, Paula VS, Oliveira JM, Niel C, Gaspar AMC. Hepatitis A virus infection in hepatitis $\mathrm{C}$ Brazilian patients. J Infect. 2003; 47:125-8. 